\title{
BIOMETRIC ELECTION TECHNOLOGY, VOTER EXPERIENCE AND TURNOUT IN GHANA
}

\section{Samuel Adams and William Asante}

Samuel Adams is Professor and Dean in the School of Public Service and Governance, Ghana Institute of Management and Public Administration, Accra

William Asante is a PhD Candidate in the School of Research and Graduate Studies, Ghana Institute of Management and Public Administration, Accra

\section{ABSTRACT}

This study investigates the experiences of voters with election technologies such as the biometric system for voter registration and verification (BVRV), as well as whether such technologies affected both turnout and trust in Ghana's 2012 and 2016 elections. The paper also explores whether the introduction of BVRVs increased or decreased levels of voter trust in the Electoral Commission (EC) and election outcomes. Using both primary and secondary data, the study found that the introduction of BVRV in election management in Ghana influenced the turnout for both the educated and the uneducated. While most of the former were eager to experience this novel approach, the same could not be said of the latter, less educated group. The study noted that state institutions do not take population diversity into consideration when introducing technological interventions. They take it for granted that citizens have the same capability, resulting in the marginalisation and neglect of a large section of the populace; this lack of trust in turn has a negative effect on voter turnout. The study recommends that such inequities in society should be taken into consideration when implementing interventions like BVRV in election management, specifically in Ghana but also in other African countries with similar socioeconomic and political conditions.

Keywords: election technologies, voter turnout, Ghana, voter experience

\section{INTRODUCTION}

Elections are an indispensable and foundational feature of modern democracy. They empower the people to select their chosen candidates to steer the affairs of 
a state or country. Democratic elections require a state that is able, on the basis of pre-existing records or through an ad hoc procedure, to compile a reliable voters' list; and also implies that voters are able to identify themselves to the polling station staff, usually by showing voter cards or national identity documents (IDs). This important process often eludes developing countries as they demonstrate persistent difficulties in registering voters and establishing their identities. These difficulties emanate from the fact that no trustworthy system of national identification exists (Akpan \& Adagba 2018). For these reasons there is a rising trend towards modernising voter registration systems as part of electoral reform in most developing countries (Rosenberg \& Chen 2009).

In Ghana, election reform is not a recent phenomenon but has been part of the electoral process since the commencement of the Fourth Republic in 1992. Ghana's election management body (EMB) known as the Electoral Commission (EC) has initiated steps to build confidence in the electorate after the faulty 1992 elections that resulted in the boycott of the parliamentary elections by the opposition parties (Boafo-Arthur 1995; Ayee 1997). The 1992 election is generally acknowledged as faulty because voter identification was haphazard and left to the discretion of election officials (Asante 2008), which made it difficult to detect impersonation and double voting. However, prior to the 1966 elections the EC began to streamline the voter registration process by introducing photo ID cards for voters in the ten regional capitals and ten selected rural constituencies. The rest of the population were then issued thumb-printed ID cards due to funding constraints (Asante 2008). Prior to the 2000 and 2004 elections photo ID cards had been issued; but the unique feature in 2004 was that aside from the provision of a photo ID card, voters had their photographs embossed against their biographical details on the main register. This helped to reduce impersonation and double voting, and was continued in subsequent elections, though not without controversy, until 2012 when the biometric system for voter registration and verification (BVRV) was introduced. Measures were however introduced to make the biometric reform operational, leading to the replacement of the existing Public Elections Regulations otherwise referred to as Constitutional Instrument (C. I.)15 which had governed public elections since 1996. The new law C.I.75 gave legal effect to the introduction of the biometric system, resulting in the popular mantra by the EC 'No Verification No Voting' (NVNV). Despite the promising nature of the BVRV in Ghana's elections, one key challenge has been the EC officers' lack of consistency in applying the NVNV law. This led the major opposition party, the New Patriotic Party (NPP) to contest the outcome of the 2012 elections in court.

Since December 2018 Ghana's ten geographical regions have been augmented to sixteen; each region is also divided into metropolitan, municipal and 
district assemblies (MMDAs) in order to bring the government closer to the people and to facilitate service delivery by the central and local governments (Bening 2012). Constituencies are geographical divisions solely for the election of the representatives to the national legislature (see Article 47 of Ghana's 1992 Constitution). The distinction between urban and rural area is based predominantly on population size; an urban area has a population of 5000 or more whereas a rural area has a population of less than 5000 (Ghana Statistical Service 2014).

Electoral reforms may be an improved response to the desires and expectations of the electorates and occur when change is intended to foster and enhance impartiality, inclusiveness, transparency, integrity or accuracy of the electoral process (International IDEA 2006). These reforms have been outlined by authors such as Frempong 2008; Gyekye-Jandoh 2013; Debrah 2015; and Botchway and Kwarteng 2018. However, they have largely focussed on a cursory list of various reform initiatives in Ghanaian elections which supported the notion that reforms are a result of elite initiation, bargaining and consensus.

The introduction of biometric technology (BT) for identification and verification in Ghana's elections has also received attention in the extant literature (Golden, Kramon \& Fosu 2014; Boateng \& Akaba 2015; Dorpenyo 2016; Effah \& Debrah 2018); but these studies do not directly discuss the experiences of voters with BT in the 2012 and 2016 elections. For instance, Effah and Debrah (2018) examined the failure of Ghana's first attempt to use BT for voter identification and verification in its 2012 general elections. Employing activity theory as an analytical lens and interpretive case study for the methodology, these authors found that the effectiveness of biometric technology to provide reliable identification does not depend solely on its technical qualities but also on real-time connectivity between registration centres and an electronic national register.

Dorpenyo's (2016) study on the introduction of BT in Ghana's 2012 elections focussed on the role of technical communicators in technology adoption, centering his argument on the technical documents that accompany the biometric device. Also, Boateng and Akaba (2015) use Ghana's 2012 election to explore the difficulties and benefits of introducing BT in elections. Their study identified the slowing down of the voting process, inadequate understanding of the biometric system and breakdown of biometric verification devices as some of the difficulties. The benefits included substantial prevention of double voting and voting without relevant IDs. EC staff could use their discretion and allow voters to vote when they did not have the required ID, providing there were two or more witnesses to support their claim. This system was however open to abuse as EC officials were often intimidated by politicians who exploited this option. BT was designed to curb this malpractice. 
Golden et al. (2014) investigate patterns of biometric identification machine breakdowns in Ghana's 2012 elections and found that machine malfunction facilitated election fraud, including overvoting and ballot stuffing, especially where election observers were not present.

This paper departs from the previous studies mentioned above by investigating the experiences of voters with BT during the 2012 and 2016 elections. Specifically, the study's purpose is firstly, to identify whether the introduction of the BVRV prevented or encouraged the electorates to vote in 2012 and 2016; and secondly, to assess whether the introduction of the BVRV in Ghana's elections has increased or decreased the level of electorate trust in the EC and election outcomes. Using a qualitative case study approach, the outcome of this study is expected to highlight the social justice implications for election management in a developing country. The study argues in favour of a more humanitarian and participatory approach in implementing BVRV technology, highlighting the plight of the disadvantaged in the implementation process and suggesting remedies for similar programs in future.

The study reviews relevant literature on election technologies and election management, election technologies, and voter turnout, followed by a description of the research methodology, and study's findings. Finally, the conclusion offers pointers for policy practitioners and technical communicators in the future.

\section{ELECTION TECHNOLOGIES AND ELECTION MANAGEMENT}

Many countries such as Australia, Brazil, Canada, Philippines, and the United States of America (US) use various forms of computer technology in national elections (Card \& Moretti 2007; Boateng \& Akaba 2015). This is referred to as computerised democracy, one in which part of the electoral process is based on information technology (Boateng \& Akaba 2015). For the most part this application of technology is part of an attempt to redress electoral anomalies such as voting fraud, rigging, and impersonation. For instance, the difficulty of counting the ballots in Florida during the 2000 presidential election in the US drew the nation's attention to voting technology. Backed by funding from a new federal law, the Help America Vote Act of 2002, many US states have responded by installing touch-screen voting machines (Card \& Moretti 2007) aimed at ensuring greater transparency, trust and openness in governance and democracy.

In the same vein biometric identification systems are widely used for voter registration in developing countries. The International Institute for Democracy and Electoral Assistance (IDEA) observed that in 2014, 38 low and middle-income countries used biometrics to register voters and the number continues to rise (IDEA 2014). Specifically, different kinds of biometric infrastructure have been used in Zambia, Nigeria, Uganda, Mongolia, Fiji, Bangladesh, Ghana, Mali, Kenya, 
Cameroon, Sierra Leone, Mozambique, Zambia, Malawi, Rwanda, Senegal and Mauritania (IDEA 2017; Nwangwu 2015).

In a study focused on sub-Saharan Africa, Gelb and Diofasi (2016, p. 2) observed that biometric elections have been generously supported by donors. Their study focussed on the costs and benefits of applying BT in elections, particularly the potential of the technology to reduce the probability of seriously disputed elections that escalate into violence. The authors identified that BT may reduce the likelihood of serious post-election violence and as such is a worthwhile investment. Nonetheless, they identified two weaknesses of BT: first, using sophisticated technology does not necessarily increase the credibility or the fairness of elections and can even undermine it. The second concern is that costly one-off electoral registrations may divert attention and funding away from supporting civil registration and financially sustainable national identification systems that should provide the basis for voters' rolls.

Olurode (2017) acknowledges that elections in Nigeria are a matter of life and death because of their zero-sum game. The stakes are so high that electoral malpractices are common; when election technology, specifically electronic card readers were introduced in 2015, they prevented electoral manipulations and fraud. Olurode further opines that this technology paved the way for more credible and competitive elections in Nigeria. Akpan and Adagba (2018) share similar views and add that technology such as Information Communication Technology (ICT) can assist in the management of the electoral process so as to curb electoral malpractice.

In Ghana, Golden et al. (2014) investigate patterns of biometric identification machine breakdowns in the 2012 national elections. The authors observe that in a polling station with a randomly assigned election observer, machines were about $50 \%$ less likely to experience breakdown than in polling stations without observers. They again found that machine malfunction in turn facilitated election fraud including overvoting and ballot stuffing, especially where election observers were not present. These results corroborate the argument that partisan competition may promote election fraud in fledgling democracies. They further demonstrate that technological solutions are valuable but insufficient in solving political problems when political interests have the incentive and ability to manipulate the technology.

Effah and Debrah (2018) analyse why BVRV failed in Ghana's 2012 elections. They found that for BVRV to be effective in delivering credible elections accepted by all stakeholders, it should not depend solely on the technology but on how rapidly registration centres are able to connect with the electronic national register. More importantly, Boateng and Akaba (2015), Effah and Debrah (2018) and Dorpenyo (2016) concur that the application of BT in Ghana's 2012 elections 
was a failure; however, their opinions vary on how they identify this failure. Whereas Boateng and Akaba conducted a postmortem to identify BVRV's benefits and drawbacks, Dorpenyo looked at the implementation of BT and the role of technical communicators. This study contributes to existing knowledge by considering the implementation of BVRV in the 2012 and 2016 elections from the voter perspective and agrees with the above authors that Ghana's 2012 elections were faulty. However, it goes a step further to suggest that the 2016 elections were a major improvement, hence its outcome was accepted by all stakeholders.

The above discussions reveal that no single BT is expected to effectively meet the requirement of precision, cost, privacy concerns, legal complexities and pragmatism (Jackson 2009; Uludag et al. 2004). Magnet (2011) concurs, claiming that the biometric system is subject to major errors that include false acceptance rate (i.e. of an unauthorised user), false rejection rate (incorrect rejection) and the failure to enroll (machine error). The data gathered and the extant literature attest to the fact that though biometric technology has not always performed optimally it has been crucial in minimising double voting, impersonation, fraud and rigging, in election management.

A clear distinction exists between voter registration and verification regarding BT adoption in Ghana. Voter registration was phase 1 of the BVRV which began with identity checks, followed by the capture of biographical data, fingerprints and photograph of each voter. Verification followed on election day when voters were verified before being allowed to vote (Effah \& Debrah 2018).

\section{ELECTION TECHNOLOGIES AND VOTER TURNOUT}

Earlier studies to demonstrate factors or variables having causal effect on turnout include, but are not limited to the assumption that voters turn out when they realise that their vote might decide the elections, and also because of a feeling of civic responsibility (Riker \& Ordeshook 1968). In addition, rational wealthmaximising behaviour by the electorate may also lead to high voter turnout (Barzel \& Silberberg 1973; Filer \& Kenny 1980). A study by Knack (1994) tested the assumption that unpleasant weather conditions (rain) on election day reduces turnout; however, the result showed that rain does not significantly reduce the probability of voting. Farber (2009) sought to investigate whether making election day a national holiday increases voter turnout; the findings however revealed that an election holiday on its own does not necessarily increase voter turnout. Other studies on voter turnout consider the relationship between the closeness of elections and voter turnout (Matsusaka 1993; Shachar \& Nalebuff 1999), and the effect of legal changes such as that of the US Constitution on voter participation, specifically the $24^{\text {th }}$ Amendment (cancellation of the poll tax) and 
26th Amendment (lowering the voting age from 21 to 18 years) (Ashenfelter \& Kelley 1975; Filer, Kenny \& Morton 1991). However, the effect of election technologies on voter turnout (Roseman \& Stephenson 2005) is an area that has not received much attention in the literature. One of the objectives in this study is to add to the existing knowledge by investigating whether the introduction of BT in Ghana's 2012 and 2016 elections in anyway influenced turnout among the study's sampled voters.

The study by Roseman and Stephenson (2005) is one of the earlier attempts to investigate whether technology influences voter turnout. The authors revealed that after the Florida election fiasco of 2000, there was a strong emphasis on replacing voting equipment perceived as inferior (e.g. punch card ballots) with more technologically advanced methods. Some voters, especially the elderly, were apprehensive about computerised voting, which led to a low turnout of elderly voters. However, this situation is probably temporary as ongoing education and experience will help the elderly to adapt to the technology. Allers and Kooreman (2009) corroborate the work of Roseman and Stephenson in some respects, in that electronic voting had a small positive effect on voter turnout in Dutch elections initially but this cannot be guaranteed in the future.

Mugica (2015) observes that in automated elections, voters from all age groups consistently report that it is easier to vote electronically than with pen and paper. In addition, touchscreens facilitate voter turnout for the illiterate who can simply touch the picture of their candidate's face or the colour of their party with a finger. As a result, voters with disabilities are lobbying governments for computer-based systems which will allow them to vote without assistance.

\section{METHODOLOGY}

This study uses qualitative research design which emphasises textual analysis in social research (Bryman 2012). The purpose of qualitative research is to understand or explain behaviour and beliefs, identify processes and understand the context of people's experiences (Hennink, Hutter \& Bailey 2011).

According to Creswell (2007), different approaches for qualitative research include phenomenology, narrative, grounded theory, case study and ethnography. The case study is deemed appropriate for this study as it provides detailed, indepth collection of data involving different sources of information. Ghana is chosen as the case study to investigate voter experience with BT during their 2012 and 2016 elections. It is a lower middle-income country where urban areas have a higher literacy rate than rural areas and where elections are seen as a zero-sum game. This is also the case in Nigeria, and we are of the view that any country with similar conditions to those in Ghana could benefit from this study. 


\section{Data Collection and Analysis}

The study relied on semi-structured interviews as the primary means of field data collection. These interviews were conducted in two of the swing regions of Ghana, Greater Accra and Central. Swing regions in this context are those that are not committed to voting for a particular party or candidate. In each of these regions, one rural and one urban constituency were purposively selected. In the Greater Accra region (GAR), the Korle Klottey Constituency was selected to represent the urban constituency, and the Shai Osudoku Constituency to represent the rural constituency. In the Central Region (CR), the Cape Coast North Constituency was selected to represent the urban constituency and Senya West the rural constituency. In each of the urban and rural constituencies in the two regions, eight categories of interviewees were sampled and interviewed (see Table 1 below).

Table 1: Demographics of Respondents

\begin{tabular}{|c|c|c|c|c|c|}
\hline \multicolumn{3}{|c|}{ Rural } & \multicolumn{3}{c|}{ Urban } \\
\hline $\begin{array}{c}\text { Educated } \\
\text { Voters }\end{array}$ & $\begin{array}{c}\text { Uneducated } \\
\text { Voters }\end{array}$ & EC Officials & $\begin{array}{c}\text { Educated } \\
\text { Voters }\end{array}$ & $\begin{array}{c}\text { Uneducated } \\
\text { Voters }\end{array}$ & EC Officials \\
\hline 8 & 8 & 1 & 8 & 8 & 1 \\
\hline
\end{tabular}

Source: Author's compilation 2018

The use of 'educated' here refers to informants who have completed senior high school and above, whereas the term 'uneducated' is used for interviewees with no education or who have dropped out from basic (primary) education.

Two EC officials were also selected and interviewed, one from the Shai Osudoku District (Greater Accra Region) and the other from the Cape Coast Metropolitan District (Central Region). One EC official represented the Urban District (Cape Coast Metropolitan) whereas the other represented the rural (Shai Osudoku). In total 34 interviewees took part in the study. The selection of informants took into consideration their age, voting experience in the last two elections (2012 and 2016) and citizenship (whether informants were Ghanaians). All interviewees were assured that the information they gave was strictly confidential and for academic purposes only. Before the interviews, the study's objective was clearly explained to the interviewees after which they were asked to sign the consent form indicating their willingness to continue. Each interview lasted between 35 and 60 minutes and took place at venues of their choice, mostly their own homes and public places such as bars and restaurants. 
Secondary data was obtained from nationwide surveys by Afrobarometer and a team of researchers from the Ghana Institute of Management and Public Administration (GIMPA). The Afrobarometer Round 6 survey used in this study was conducted in Ghana by the Center for Democratic Development (CDD-Ghana). The survey is sourced from a nationally representative sample of adult citizens with all respondents randomly selected. Face-to-face interviews were conducted in the language of the respondent's choice. Standard questionnaires were used and allowed for comparisons across countries and over time. A sample size was chosen of 2400 with a margin of error of $\pm 2 \%$ at a $95 \%$ confidence level. Fieldwork for Round 6 in Ghana was conducted between May and June 2014.

The 2017 survey from GIMPA was also designed as a representative nationwide sample survey on voting behaviour with a sample size of 3200 voters on the 2016 general elections in Ghana at a confidence level of 95\% and a confidence interval of two. The survey respondents were drawn from 95 out of 275 constituencies in the administrative regions. In each region, at least onethird of the total constituencies were selected using simple random procedure. The sample of 95 constituencies represents $38.8 \%$ of the total 275 constituencies. In terms of the distribution of the survey questionnaires, a total of 3200 were allocated based on the region's proportionate share of the national results of the total votes cast in the 2016 general elections. Thus, the Ashanti region had the highest percentage (22\%) while Upper West had the lowest percentage (3\%). In all, 3160 questionnaires were returned representing a 98.8\% response rate.

Subsequently, the household was the primary sampling unit and respondents were those individuals who had voted during the 2016 election. The Household Selection Kish Grid was used to select households based on a specific interval of three and five for rural and urban areas respectively. The respondent Kish grid was further used to select one respondent from each household where there were more qualified respondents. To ensure gender balance, the research assistants were tasked to repeat the process until the 1580 respondents had an equal number of females and males. The study also randomly selected an equal number of 1580 respondents from rural and urban constituencies. Tables 2 to 5 show a section of the survey respondents' biodata.

Table 2: Age of Respondents

\begin{tabular}{|c|c|c|}
\hline Responses & Frequency & Percent \\
\hline NR & 9 & 0.28 \\
\hline $18-30$ & 929 & 29.40 \\
\hline $31-40$ & 1087 & 34.40 \\
\hline
\end{tabular}




\begin{tabular}{|c|r|r|}
\hline $41-50$ & 615 & 19.46 \\
\hline $51-60$ & 375 & 11.87 \\
\hline $60+$ & 145 & 4.59 \\
\hline Total & $\mathbf{3 1 6 0}$ & $\mathbf{1 0 0 . 0 0}$ \\
\hline
\end{tabular}

Source: Survey Data, 2017.

Table 3: Gender of Respondents

\begin{tabular}{|l|c|c|}
\hline Responses & Frequency & Percent \\
\hline Male & 1580 & 50.00 \\
\hline Female & 1580 & 50.00 \\
\hline Total & $\mathbf{3 1 6 0}$ & $\mathbf{1 0 0 . 0 0}$ \\
\hline
\end{tabular}

Source: Survey Data, 2017.

Table 4: Location of Constituency

\begin{tabular}{|l|c|c|}
\hline Responses & Frequency & Percent \\
\hline Urban & 1580 & 50.00 \\
\hline Rural & 1580 & 50.00 \\
\hline Total & $\mathbf{3 1 6 0}$ & $\mathbf{1 0 0 . 0 0}$ \\
\hline
\end{tabular}

Source: Survey Data, 2017.

Table 5: Level of Education

\begin{tabular}{|l|c|c|}
\hline Responses & Frequency & Percent \\
\hline NR & 24 & 0.76 \\
\hline No Formal Education & 336 & 10.63 \\
\hline Primary Education & 151 & 4.78 \\
\hline JSS & 540 & 17.09 \\
\hline SSS & 540 & 17.09 \\
\hline Teacher Training/Polytech & 231 & 7.31 \\
\hline Tertiary & 1338 & 42.34 \\
\hline Total & $\mathbf{3 1 6 0}$ & $\mathbf{1 0 0 . 0 0}$ \\
\hline
\end{tabular}

Source: Survey Data, 2017. 
Analysis of the primary data used the qualitative content analysis technique, which according to Hsieh and Shannon $(2005$, p. 1278) is a '... method for the subjective interpretation of the content of text data through the systematic classification process of coding and identifying themes or patterns'. After collecting the data, it was transcribed and then a narrative was derived from the transcription. Interview notes were coded in which similar codes were clustered into themes representing the objectives of the study. The data from the secondary sources [representative nationwide surveys] were analysed using the descriptive statistical method with the help of the SPSS version 23 software package to develop frequency distribution tables and line graphs.

\section{FINDINGS}

The following section analyses the findings based on pre-selected themes derived from the objectives: BVRV technology and voter experience and turnout; perceptions of trust in BVRV technology; and perceptions of trust in the EC.

\section{BVRV Technology and Voter Experience and Turnout}

The study's investigation into whether BVRV prevented or encouraged the electorate from voting in the 2012 and 2016 elections had various responses after interactions with key informants at research sites.

A female interviewee in the 25-35 age group, with tertiary education (teacher training school) in the Cape Coast North Constituency in the Central Region pointed out that:

I think the introduction of the BVRV encouraged me to vote in the 2012 elections because I was very anxious to know how it really works ... I think the BVRV did not encourage me to vote in the 2016 elections because after my experience with 2012, it wasn't the BVRV that encouraged me rather it is because it was my right to vote.

A male public servant from Senya West recounted that:

In 2012, it was quite an experience, the process was very easy and the time spent was minimal, even though there were challenges. For the 2016 elections, everything was ok.

Another male in the 35-45 age group with tertiary education from the Korle Klottey Constituency, described his experience: 
During the 2012 elections, I personally did not have any problems, I had read a lot about the BVRV on the internet and in the newspapers...

Most of the key interviewees, and in particular the better-educated and technologically savvy voters, shared similar views. This suggests that they were curious to have first-hand unique experience of this technology. This is consistent with the findings of Roseman and Stephenson (2005) that the introduction of new technology influences voter turnout. On the same trajectory the assertion of the interviewee above that she voted in 2016 because it was her right to do so, supports the findings of Riker and Ordeshook (1968) that voters are likely to vote because they feel some civic responsibility.

A male interviewee with tertiary (university) education in the 35 to 45 -year group, from the Korle Klottey Constituency, Greater Accra mentioned that;

I think the introduction of the BVRV encouraged me to vote in the 2012 elections. I thought 2012 election will be one of the most credible elections in the country because of the BVRV but people managed to manipulate the election results especially the presidential. I was not pleased with the outcome.

This supports the argument that no single biometric is expected to meet the requirement of completely eliminating fraud and manipulation (Jackson 2009; Uludag et al. 2004), cementing the argument that the occurrence of errors with BVRV is likely. Magnet (2011) notes that the biometric system is subject to three forms of errors i.e. false acceptance, false rejection and failure to enroll.

The same informant went further to express his experience with the BVRV technology in the 2016 elections:

I think the introduction of the BVRV encouraged me to vote in the 2016 elections. Before 2016 election, a lot of education about the BVRV was held for all stakeholders and they understood the dynamics of the BVRV. This gave me 100\% confidence that the 2016 election will be more credible than the previous one (2012).

In addition, a male in the Senya West constituency with educational background up to university level commented:

On a scale of first to fifth, I rank the introduction of the BVRV as the fourth push factor that made me vote in the 2012 elections, on the other hand, I rank the introduction of the BVRV technology as the third push 
factor that made me vote in the 2016 elections. This is because 2012 was a good attempt with the BVRV technology but 2016 was better, less complaints.

In contrast with the above experiences, another male informant in the 35 to 45-year group, educated up to senior high school and from the Shai Osudoku constituency commented:

I do not think the introduction of the BVRV encouraged me to vote in the 2012 elections. I did not vote because of the introduction of the BVRV, rather because it is my right to vote ... I do not think the introduction of the BVRV encouraged me to vote in the 2016 elections, it didn't in anyway encouraged me to vote.

This confirms the issue of civic responsibility as described by Riker and Ordeshook (1968).

A male aged between 45 and 55 years with no educational background, from the Korle Klottey Constituency in Greater Accra, asserted that:

I was very nervous when I first heard of the introduction of the BVRV technology in our elections in 2012. I complained bitterly because I did not know anything about it and how the experience will be like. Initially I thought it was a strategy to rig the elections. I didn't know it was to strengthen the election process. I was saved by my son who is more educated and knowledgeable about the process.

A similar experience was recounted by a key informant, a woman in the 55 to 65-year group with no educational background, in the Senya West Constituency. She expressed disappointment with how she felt left out, asserting that:

I was frightened when I heard on radio that now before you vote, you need to be checked by a computer before you can vote. I was discouraged totally to vote. I did not go out to vote in the 2012 elections but in 2016 my granddaughter encouraged me, and assisted me to the polling station.

An interviewee from Shai Osudoku with no educational background and between the ages of 55 and 65 , recounted that:

Immediately I heard this on radio, I said to myself, this politicians are at it again to make life miserable for some of us...my nephew had 
experienced this same computer when he finished the Junior High School, he was placed at a school in Tamale (northern part of Ghana) even though he did not choose that school; so seriously I wasn't enthused about the policy at all and so I didn't vote in 2012.

Another interviewee with no educational background from Cape Coast North Constituency, described her experience thus:

In the first election when the biometric machine was used (referring to the 2012 elections); I mustered courage to vote after I had been convinced by one of my neighbors that it was a simple technology, however, putting my finger on the machine to verify me was frightening.

These statements clearly indicate that while some of the informants benefitted from the introduction of BVRV technology, others, particularly the uneducated, felt disadvantaged and needed assistance. One notable point is that both the GAR and CR have a high proportion of people who had attended or were attending school in both urban and rural areas: GAR 90.9\% urban, $81 \%$ rural; CR $83.8 \%$ urban, $81 \%$ rural (Ghana Statistical Service 2013). This promising statistic suggests that any effort to educate the electorates on BVRV would have been widespread and easily understood. Aside from this, older Ghanaians have lower literacy rates than younger ones (Ghana Statistical Service 2013). This was also reflected in the sampled constituencies as most of the uneducated interviewees are in the older age bracket. Uneducated and/or aged informants were frequently at a disadvantage and unfortunately institutions like the EC and National Commission for Civic Education (NCCE) failed to make them feel part of the election process, in particular BVRV technology. Fear of the unknown discouraged informants from exercising their constitutionally mandated right to vote. This is consistent with the argument of Slack and Wise (2005) that 'who or what someone is' affects technology use because technologies are developed to meet user needs.

Thus, when individuals who are expected to benefit from technology are side-lined in terms of access to appropriate information on technology usage, then the purpose of acquiring that technology has not been met. Confirming this view Winner (1989) also noted that technologies are not merely aids to human activity but are powerful forces reshaping that activity and its meaning. In similar vein, the argument is that had the disadvantaged been better educated they would have found BVRV simple, which would have encouraged voter turnout. The observation by Mugica (2015) strengthens the above argument that technology, if appropriately used, could increase the turnout of voters with disabilities, the uneducated, poor and destitute, thus encouraging inclusivity in the democratic process. 


\section{Perceptions of Trust in the EC and Election Outcome}

The issue of whether the introduction of BVRV has affected voter trust in the EC and election outcomes needs to be assessed in terms of the general trend of trust in the EC from 2002 to 2014, based on Afrobarometer data (see Figures 1 and 2 below). Two trust trends have been identified. The first trend as illustrated by Figure 1 looks at the percentage of respondents that have expressed little or no trust for the EC since 2002. The line graph reveals that from $2002,41 \%$ of respondents did not trust or had little trust in the EC, but this fell in 2005 to $21 \%$, possibly because of innovations introduced in the 2004 elections such as embossing the photographs of voters against their biographical details in the main register. Since 2005, the percentage of respondents who had little or no trust in the EC has continued to rise steadily to 59\% in 2014 (see Figure 1 below). Figure 2 also shows that in 2005, respondents expressed a high level of trust for the EC (75\%), but since then there has been a downward trend to $37 \%$ in 2014 . This low percentage rate may be due to EC inefficiencies in conducting the 2012 elections, with major stakeholders disagreeing on the results thus allowing the courts to intervene.

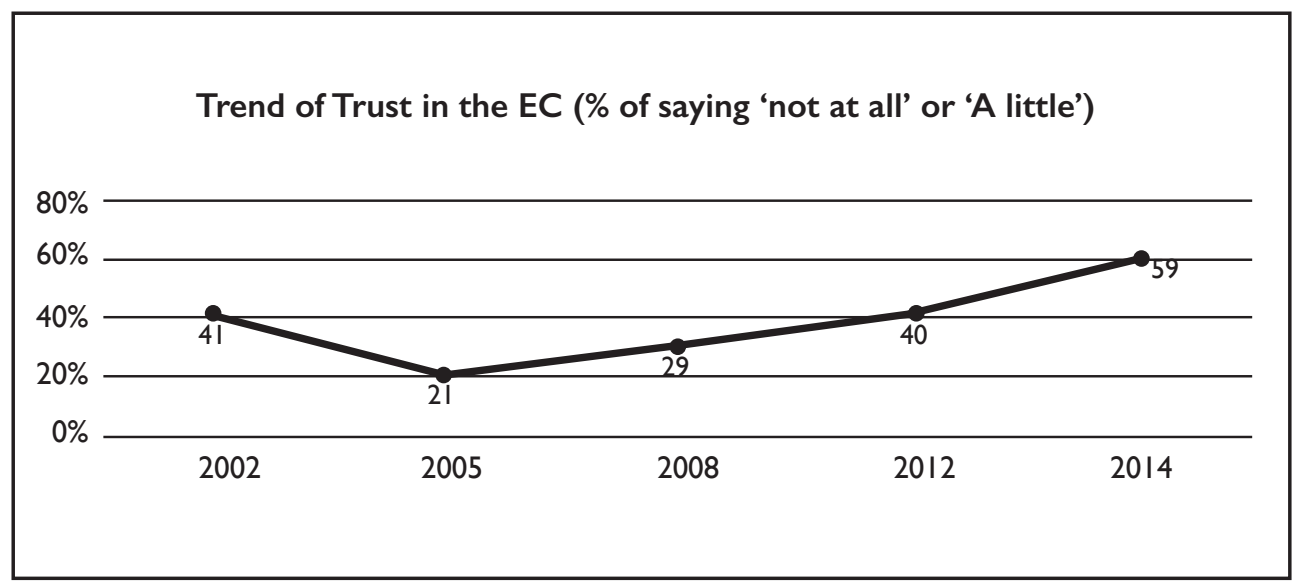

Source: Afrobarometer (2016)

Figure 1: Trend of Trust in the EC 


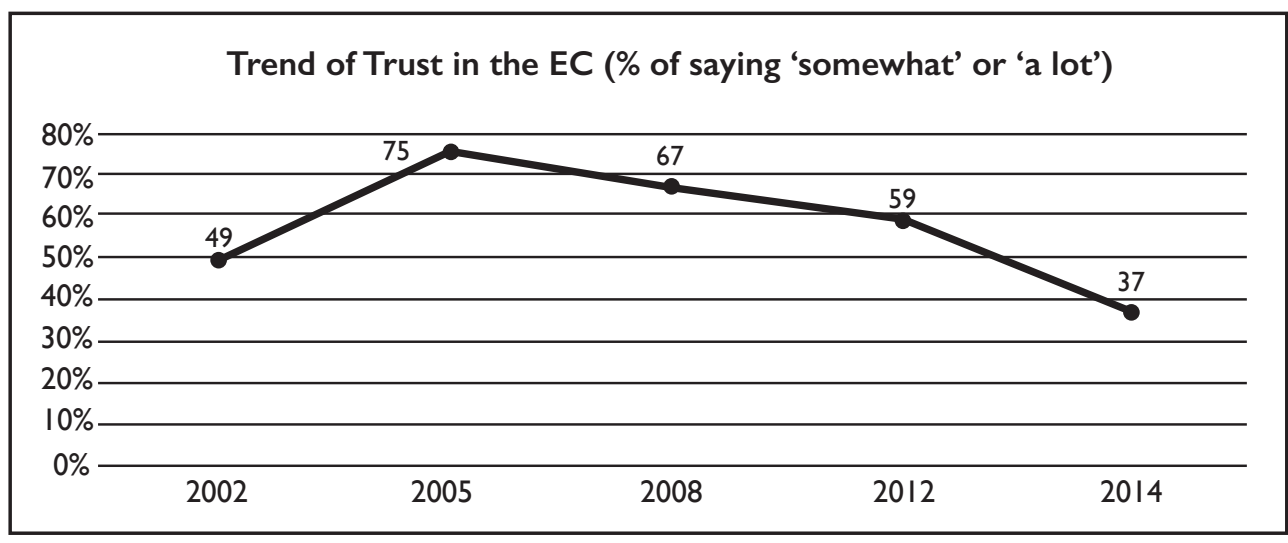

Source: Afrobarometer (2016)

Figure 2: Trend of Trust in the EC

The level of trust in the EC illustrated above shows that from 2005 onwards the percentage of respondents who had little or no trust in the EC kept increasing, while those who expressed somewhat or a lot of trust kept reducing. This may be as a result of the many questions that remained unanswered in the minds of the electorate. The key issue was the reliability of the voters' roll.

The GIMPA Survey also gauges the level of trust for the EC after the 2016 elections. Table 6 shows that $47 \%$ of respondents stated that they have huge trust in the EC, 30\% indicated that to some extent the EC could be trusted, $17 \%$ mentioned that they trusted the EC a little, while only $4 \%$ of the respondents indicated no trust at all for the EC. This is an improvement on the percentages in Figures 1 and 2, showing that those who did not trust the EC kept decreasing and those who trusted the EC kept increasing from 2005 onwards, suggesting that the EC gradually gained the confidence of the electorate after the 2016 elections. This is because major stakeholders agreed on the outcome of the elections, with both domestic and international election observers describing it as free and fair - unlike the contested election results in 2012 (Effah \& Debrah 2018; Boateng \& Akaba, 2015). Despite the adoption of the BVRV for the 2012 and 2016 elections, the electorate remains divided on the issue of trust. For example, one educated urban dweller in the Korle Klottey Constituency remarked:

I do not have confidence [trust] in the EC to conduct credible elections. This is because even with the introduction of the BVRV there have been incidents of electoral fraud. I see the EC as being politically influenced. 
This view was supported by a female interviewee (with no educational background) in the Shai Osudoku Constituency:

I do not have confidence [trust] in the EC to conduct credible elections because it is influenced by government and as such has no credibility. Imagine how the EC delayed in the final declaration of the results (referring to election 2016) even after all the media houses had collated about $95 \%$ of the results from the 275 Constituencies.

On the other hand, in the same Greater Accra Region a male interviewee educated to the tertiary level at the Korle Klottey Constituency mentioned that:

I have confidence in the EC to conduct credible elections; this is because political parties representatives and the media are given the opportunity to enter the ECs strong room to monitor the results of the elections...The introduction of the BVRV has increased my confidence in the EC; this is because the introduction of the BVRV has eradicated the practice of one person voting more than one.

Similarly, a secondary school leaver in the Shai Osudoku Constituency states that:

The introduction of the BVRV has not reduced my confidence in the EC. It has rather increased my confidence in the EC especially in the final results (referring to election 2016). It shows the true reflection of what happened at the various polling stations.

These responses depict the dynamics of what should happen in a typical swing region. That is to say, opinions should be diverse and based on unique experiences and access to information. Swing region Greater Accra demonstrates this in its voting pattern by alternating between the two major political parties in Ghana, the New Patriotic Party (NPP) and National Democratic Congress (NDC). The NDC has won four of the seven presidential elections in the Fourth Republic (1992, 1996, 2008 and 2012), with NPP winning the remaining three (2000, 2004 and 2016). The CR depicts a similar picture (Frempong 2015). From the foregoing, it appears that whenever a party wins these regions (GAR and CR), the presidential candidate of that party wins the overall national election. It must however be mentioned that although the GAR appears to be a swing region, some of the constituencies do not. A typical case is that of Shai Osudoku which consistently voted for the NDC from 1992 to 2016. To have interviewees in the Shai Constituency showing 
diverse opinions on the management of elections alongside experiences with the BVRV at a time when their favourite political party was in power (NDC), depicts the growing maturity of the Ghanaian voter. They are stating their opinions without being influenced by the broader context in which they find themselves. This further suggests that opinions on election management are not always linked to partisan politics or the context in which the respondent finds him- or herself.

Furthermore, some of the interviewees who criticised EC performance in its election management role, argued that it was dancing to the tune of the incumbent NDC regime. This may have been because the regime's communicators defended the efforts of the EC at every opportunity; but also because of over-reliance by the EC on government funding and the appointment of the EC chair by the president prior to the 2016 elections. Most citizens saw these as an incentive for the government to manipulate the $\mathrm{EC}$, hence leading to the allegation that the undue delay prior to the declaration of the 2016 results was intended to rig the elections in favour of the incumbent NDC government.

Table 6: Trust in the EC

\begin{tabular}{|l|c|c|}
\hline Responses & Frequency & Percent \\
\hline A lot & 1486 & 47.31 \\
\hline Somewhat & 936 & 29.80 \\
\hline A little & 532 & 16.94 \\
\hline Not at all & 128 & 4.08 \\
\hline Don't know & 59 & 1.88 \\
\hline Total & $\mathbf{3 1 4 1}$ & $\mathbf{1 0 0 . 0 0}$ \\
\hline
\end{tabular}

Source: Survey Data, 2017.

\section{Perceptions of Trust of BVRV Technology}

One of the major reasons for the introduction of BVRV was to inspire trust in the voters' roll. Respondents were thus assessed on their level of trust in the voters' roll after their experience with the BVRV in the 2012 and 2016 elections. The result was that $46 \%$ indicated that they trusted the voters register a lot, whereas $45 \%$ responded that they did not to have much trust in the voters' roll (Table 7). This clearly supports the findings that respondents' trust in the EC and voters' roll has not improved as much as expected. Respondents would have been expected to have a very high level of trust in the register and the EC after the adoption of the BVRV technology in 2016 (see Tables 6 and 7), but this was not so. 
Table 7: Trust in the Voters' Roll

\begin{tabular}{|l|c|c|}
\hline Responses & Frequency & Percent \\
\hline A lot & 1440 & 45.71 \\
\hline Somewhat & 879 & 27.90 \\
\hline A little & 531 & 16.89 \\
\hline Not at all & 168 & 5.33 \\
\hline Don't know & 132 & 4.19 \\
\hline Total & $\mathbf{3 1 5 0}$ & $\mathbf{1 0 0 . 0 0}$ \\
\hline
\end{tabular}

Source: Survey Data, 2017.

Another important issue was the assessment of respondents' perceptions of trust in the BVRV to detect electoral fraud. Table 8 indicates that $57 \%$ of the respondents replied that they have a lot of trust in BVRV technology to detect fraud, $26 \%$ stated that they trust the BVRV technology only somewhat, and only $14 \%$ of the respondents stated that they have just a little trust in the BVRV to detect fraud. That the level of trust of respondents in the BVRV technology is much higher (over $50 \%$ ) is possibly because of improved operations, as described by one educated male informant from the Korle Klottey Constituency in the Greater Accra Region:

I saw an improvement of the BVRV technology operations in the 2016 elections, the hullabaloo associated with the BVRV technology during the election 2012 which was subsequently sent to court was greatly improved in 2016. I must say the litigation process did a lot of good for election management in Ghana.

Another informant, an educated female in the Senya West Constituency, commented:

Well, the introduction of the BVRV system had some challenges at my polling station but I was confident about it that it will improve ... By 2016 during the election period, I realized the BVRV System had improved and reduced stress a little bit.

The experiences of these informants clearly indicate that their first experience with the BVRV technology was not good but incremental improvements were registered in their second experience. This suggests that the EC took into consideration the fallouts from the 2012 elections and most especially the reforms that the Supreme Court of Ghana recommended after the maiden presidential election petition 
(Asante \& Asare 2017). One of the EC officials from the Cape Coast Metropolitan District acknowledged that 'the post-2012 court case was a major contributory factor leading to the improvement in the 2016 elections. The reason being that the EC wanted to prevent another disputed election[s]'. Thus, it appears that voter trust in the EC and election outcome is gradually improving.

Table 8: Trust in the Biometric Verification System to Minimise Fraud

\begin{tabular}{|l|c|c|}
\hline Responses & Frequency & Percent \\
\hline A lot & 1788 & 56.96 \\
\hline Somewhat & 807 & 25.71 \\
\hline A little & 446 & 14.21 \\
\hline Not at all & 61 & 1.94 \\
\hline Don't know & 37 & 1.18 \\
\hline Total & $\mathbf{3 1 3 9}$ & $\mathbf{1 0 0 . 0 0}$ \\
\hline
\end{tabular}

Source: Survey Data, 2017.

\section{CONCLUSION}

This study set out to investigate first, whether the introduction of the BVRV prevented or encouraged the electorate to vote in the 2012 and 2016 elections; and second, whether the introduction of the BVRV has increased or decreased the level of trust by the electorate in the EC and election outcomes. In addressing the first objective, key informants pointed out that the BVRV encouraged them to vote because they were curious to experience new technology for the first time. This point of view emanated from most of the urban, highly educated and technology proficient informants. On the other hand, the less educated, mostly aged rural dwellers and those not exposed to technology, were apprehensive about the introduction of BVRV. Such individuals had family members rather than state institutions assisting them in how to use BVRV technology. Overall, while some of the key informants were comfortable with the BVRV, others were at a disadvantage and needed assistance. The uneducated, aged and in particular the rural informants were not encouraged initially whereas the educated - even those in rural constituencies - were encouraged to vote. They were undeterred by the new technology but curious to experience it.

Regarding the second objective, the findings indicate that a moderately high number of respondents stated that after the 2016 experience they trust the EC in conducting elections. Figures 1 and 2 also reveal that from 2002 to 2014 an increased number of respondents indicated no trust in the EC, whereas those with 
a lot of trust in the EC decreased around the same period. This decrease in trust might be as a result of the disputes emanating from the 2012 elections and the seemingly favourable posture demonstrated by the EC towards the incumbent NDC government prior to both the 2012 and 2016 elections.

The experiences of voters with BVRV technology were mixed; some interviewees indicated that the BVRV increased their confidence in the EC while others stated that it reduced their confidence in the EC concerning election management. Most of the informants pointed out that their first experience with BVRV technology was not so good; however, their second experience was an improvement. Based on the experiences of these informants, the elections of 2016 were an improvement over those of 2012. Thus, despite its challenges, the introduction of the BVRV is gradually building trust in the EC. One EC official acknowledged that the court case after 2012 was a major contributory factor leading to this improvement.

The above findings lead to some recommendations for policy makers, researchers and students of elections. With Ghana's top-down mode of BVRV implementation, it was unsurprising that the election outcome was contested in court after the 2012 elections. The elite were at the forefront of the implementation process, forcing technology on a helpless populace. There was inadequate time for public education, and professional technical communicators who could have created a more culturally inclusive outreach to aid public education and advocacy were ignored in the process.

Again, the pilot study for the test of the biometric device did not take into consideration population diversity and as a result some were excluded and the citizenry were not able to own the process. Most of the disadvantaged voters needed help from family members to keep up with the technology's implementation, or risk being marginalised and finding their right to vote curtailed.

Finally, and as acknowledged elsewhere (Banks 2005), it is not enough to provide technology to users but individuals in a particular community need to develop an understanding of 'the benefits and problems of any technology well enough to be able to critique, resist, and avoid them when necessary as well as using them when necessary' (p. 42). This can only be achieved through appropriate education, and here election experts play a crucial role in helping design education strategies so that users can understand the technology and tap into its full benefit.

From the evidence in this study, it is apparent that the EC and other stakeholders need to encourage wider consultations and broader community participation when new technologies are introduced for election management and for future elections. Ghana's diverse population, inequalities and different capabilities should be factored into implementing new and existing election technologies in order for the electorate to take ownership of the election process. 


\section{----- REFERENCES}

Afrobarometer 2016, 'Trust and Corruption in Public Institutions: Ghanaian Opinions', Available at www.afrobarometer.org.

Akpan, NE \& Adagba, SO 2018, 'Information Technology: A Contemporary Tool to Combat Electoral Fraud in Nigeria', International Journal of Social Sciences and Humanities Reviews, vol. 8, no. 1, pp. 78-87.

Asante, W \& Asare, BE 2017, 'Ghana's 2012 Election Petition and Its Outcome: A Giant Leap Towards Democratic Consolidation', in BE Asare \& AKD Frempong (eds), Selected Issues in Ghana's Democracy Vol. 1, Digibooks Ghana Ltd., Tema.

Asante, W 2008, Election Management and Democratic Growth: The Case of the Electoral Commission of Ghana, BA Dissertation, University of Ghana, Accra.

Ashenfelter, O \& Kelley, S Jr. 1975, 'Determinants of participation in Presidential elections', Journal of Law and Economics, vol. 18, pp. 695-733.

Ayee, JRA 1997, 'Election Management and Democratic Consolidation: The Case of Electoral Commission of Ghana', in JRA Ayee (ed), The 1996 General Elections and Democratic Consolidation, Department of Political Science, Accra.

Banks, AJ 2005, Race, rhetoric, and technology: Searching for higher ground, Routledge.

Barzel, Y \& Silberberg, E 1973, 'Is the act of voting rational?', Public Choice, vol. 16, pp. 51-58.

Bening, RB 2012, 'The Creation of Districts and Constituencies in Ghana: Some Pertinent Issues in the Current Dispensation', Ghana Journal of Geography, vol. 4, pp. 1-17.

Boafo-Arthur, K 1995, 'Managing Inter-Party Conflict in Ghanaian Politics: Lessons from the National Democratic Congress and the New Patriotic Party (NPP) Dialogue', in M Oquaye (ed), Democracy and Conflict Resolution in Ghana, Gold-Type Publications Limited, Accra.

Boateng, KA \& Akaba, M 2015, 'Computerising the Voting Process: On the Difficulties and Benefits of Biometric Verification Elections', Lecture Notes on Software Engineering, vol. 3, no. 1, pp. 67-72.

Botchway, TP \& Kwarteng, AH 2018, 'Electoral Reforms and Democratic Consolidation in Ghana: An Analysis of the Role of the Electoral Commission in the Fourth Republic (1992-2016)', Asian Research Journal of Arts \& Social Sciences, vol. 5, no. 3, pp. 1-12.

Bryman, A 2012, Social Research Methods, Oxford University Press, Oxford.

Card, D \& Moretti, E 2007, 'Does voting technology affect election outcomes? Touch-screen voting and the 2004 Presidential election', Review of Economics and Statistics, vol. 89, no. 4, pp. 660-673.

Creswell, JW 2007, Qualitative Inquiry and Research Design: Choosing Among Five Approaches, $2^{\text {nd }}$ ed, Sage Publications Inc., Thousand Oaks. 
Debrah, E 2015, 'Reforming Ghana's Electoral Process: Lessons and the Way Forward', Journal of Politics and Law, vol. 8, no. 1, pp. 1-13.

Dorpenyo, IK 2016, Unblackboxing Technology Through the Rhetoric of Technical Communication: Biometric Technology and Ghana's 2012 Elections, PhD Dissertation, Michigan Technological University, Michigan.

Effah, J \& Debrah, E 2018, 'Biometric technology for voter identification: The experience in Ghana', The Information Society, vol. 34, no. 2, 104-113. DOI:10.1080 /01972243.2017.1414720

Farber, SH 2009, 'Increasing Voter Turnout: Is Democracy Day the Answer?', CEPS Working Paper, no. 181, pp. 1-19.

Filer, JE \& Kenny, LW 1980, 'Voter turnout and the benefits of voting', Public Choice, vol. 35, pp. 575-585.

Filer, JE, Kenny, LW \& Morton, R 1991, 'Voting laws, educational policies, and minority turnout', Journal of Law and Economics, vol. 34, pp. 371-394.

Frempong, AKD 2008, 'Innovations in Electoral Politics in Ghana's Fourth Republic: An Analysis', in C Raventos, (ed), Democratic Innovation in the South: Participation and Representation in Asia, Africa and Latin America, CLASCO Books, Buenos Aires.

Frempong, AKD 2015, 'Elections in Ghana (1951 - 2012)', Life @ 60 Publishers, Accra. Ghana Statistical Service 2013, 2010 Population and Housing Census: National Analytical Report, Government of Ghana, Accra.

GhanaStatisticalService2014,2010Populationand Housing Census Report:Urbanization in Ghana, Available at<www.statsghana.gov.gh/docfiles/2010phc/Mono/ Urbanisation in Ghana.pdf > [ 16 May 2018]

Gelb, A \& Diofasi, A 2016, 'Biometric Elections in Poor Countries: Wasteful or a Worthwhile Investment?' Working Paper 435, Center for Global Development, Available at $<$ www.cgdev.org $>$ (6 May 2018).

Golden, M, Kramon, E \& Ofosu, G 2014, Electoral Fraud and Biometric Identification Machine Failure in a Competitive Democracy, Paper Presented at the Annual Meeting of the American Political Science Association, August 28-31, Washington, DC.

Gyekye-Jandoh, MAA 2013, 'Electoral reform and gradual democratization in Africa: The case of Ghana', African Journal of Social Sciences, pp. 74-92.

Hennink, M, Hutter, I \& Bailey, A 2011, Qualitative Research Methods, Sage Publications Ltd., Los Angeles/London.

Hobbis, SK \& Hobbis, G 2017, 'Voter Integrity, Trust and the Promise of Digital Technologies: Biometric Voter Registration in Solomon Islands', Anthropological Forum, vol. 27, no. 2, pp. 114-134, DOI: 10.1080/00664677.2017.1324287

Hsieh, H-F \& Shannon, SE 2005, 'Three Approaches to Qualitative Content Analysis', Qualitative Health Research, vol. 15, no. 9, pp. 1277-1288. 
IDEA 2006, 'Reforming Electoral Processes', in IIDEA, Electoral Management Design: The International IDEA Handbook, International Institute, Stockholm, Sweden.

International IDEA 2017, Introducing Biometric Technology in Elections, International Institute for Democracy and Electoral Assistance, Stockholm.

Jackson, LA 2009, 'Biometric Technology: The future of assurance and authentication in the lodging industry', International Journal of Contemporary Hospitality Management, vol. 21, pp. 892-905.

Knack, S 1994, 'Does rain help the Republicans? Theory and evidence on turnout and the vote', Public Choice, vol. 79, pp. 187-209.

Magnet, S 2011, When biometrics fail: Gender, race, and the technology of identity, Duke University Press, Durham, North Carolina.

Matsusaka, J 1993, 'Election closeness and voter turnout: Evidence from California ballot propositions', Public Choice, vol. 76, pp. 313-334.

Mugica, A 2015, 'The Case for Election Technology', European View, vol. 14, pp. 111-19.

Nwangwu, C 2015, Biometric Voting Technology and the 2015 General Elections in Nigeria, Paper Presented at Two-Day National Conference on 'The 2015 General Elections in Nigeria: The Real Issues' organized by The Electoral Institute 27th and 28th July.

Olurode, L 2017, 'Technology and Election Conundrum: A Case Study of Nigeria' Sociology and Anthropology, vol. 5, no. 10, pp. 799-811.

Riker, W \& Ordeshook, PC 1968, 'A Theory of the Calculus of Voting', American Political Science Review, vol. 62, no. 1, pp. 25-42.

Roseman, Jr., GH \& Stephenson, EF 2005, 'The Effect of Voting Technology on Voter Turnout: Do Computers Scare the Elderly?', Public Choice, vol. 123, pp. 39-47.

Rosenberg, JS \& Chen, M 2009, Expanding Democracy: Voter Registration around the World, Brennan Center for Justice at New York University School of Law, Available at <http://brennan.3cdn.net/3234b49c4234d92bf3_3km6i2ifu. pdf $>$ [10 May 2015].

Shachar, R \& Nalebuff, B 1999, 'Follow the leader: Theory and evidence on political participation', American Economic Review, vol. 89, pp. 525-547.

Slack, JD \& Wise, JM 2005, Culture+ technology: A primer, Peter Lang Publishing Group, Bern.

Uludag, U, Pankanti, S, Prabhakhar, S \& Jain, AK 2004, 'Biometric Cryptosystems: Issues and Challenges', Proceedings of the IEEE, vol. 92, pp. 948-960.

Winner, L 1989, The Whale and the Reactor: A Search for Limits in an Age of High Technology, University of Chicago Press, Chicago. 